\title{
CULTURA MATERIAL E INNOVACIÓN PEDAGÓGICO-CIENTÍFICA EN LA ENSEÑANZA SECUNDARIA (ESPAÑA, 1845-1939)
}

AULAS ABIERTAS. PROFESORES VIAJEROS Y RENOVACIÓN EN LA ENSEÑANZA SECUNDARIA EN LOS PAÍSES IBÉRICOS (1900-1936), por LEONCIO López-Ocón, Víctor Guijarro y Mario Pedrazuela (eds.). Madrid: Dykinson, 2018, 561 páginas. ISBN: 978-84-9148-915-3.

CIENCIA E INNOVACIÓN EN LAS AULAS. CENTENARIO DEL INSTITUTO-ESCUELA (1918-1939), por ENCARNACión MaRTínez aLFARO, LeONCIO LópezOcón Cabrera y Gabriela Ossenbach Sauter (eds.). Madrid: Consejo Superior de Investigaciones Científicas y Universidad Nacional de Educación a Distancia, 2018, 426 páginas. ISBN: 978-84-00-10401-6 y 978-84-362-7497-4.

ARTEFACTOS Y ACCIÓN EDUCATIVA. LA CULTURA DEL OBJETO CIENTÍFICO EN LA ENSEÑANZA SECUNDARIA EN ESPAÑA (1845-1930), Por VíctoR GuiJarro Mora. Madrid: Dykinson, 2018, 273 páginas. ISBN: 978-84-9148-738-8.

En el primer párrafo que en «A manera de introducción» abre Aulas abiertas, profesores viajeros y renovación de la enseñanza secundaria en los países ibéricos (1900-1936), sus tres editores - Leoncio López-Ocón, Víctor Guijarro y Mario Pedrazuela- sostienen, recogiendo lo dicho por en un texto publicado en 2010 y escrito dos o tres años antes, ${ }^{1}$ que

hasta tiempos recientes se consideraba que el estudio de la enseñanza secundaria era la «cenicienta» o el pariente pobre de la

\footnotetext{
1 Antonio Viñao, «La enseñanza secundaria», en Nuevas miradas historiográficas sobre la educación en la España de los siglos XIX y XX, eds. Jean-Louis Guereña, Julio Ruiz Berrio y Alejandro Tiana Ferrer (Madrid: Ministerio de Educación, 2010), 109-142.
} 
historiografía de la educación en España [...]. Pero en lo últimos años esta situación ha empezado a variar debido a varios factores que han hecho factible la elaboración de esta obra que presentamos a los lectores. ${ }^{2}$

Entre dichos factores, los editores señalan el «amplio movimiento de interés y estudio sobre la historia de sus centros de enseñanza» surgido entre los profesores de institutos de educación secundaria, origen no solo de diversos artículos o libros sino también, desde un punto de vista organizativo, de la Asociación Nacional para la Defensa del Patrimonio de los Institutos Históricos (ANDPIH) con sus correspondientes jornadas anuales. Junto a ello, destacan las investigaciones llevadas a cabo desde los ámbitos de la historia cultural de la educación —en especial, en lo relativo tanto a la cultura y memoria material como inmaterial de los mencionados institutos y de su profesorado-, origen y consecuencia, a su vez, del auge del museísmo pedagógico, y de una historia de la ciencia cada vez más atenta a los procesos de difusión, divulgación y transmisión de los saberes y a los medios y recursos utilizados para ello, con especial atención por el medio escolar (instituciones, profesorado, alumnado, libros de texto, material didáctico de todo tipo, exámenes, trabajos de alumnos, guías del profesorado, programaciones, testimonios, etc.).

Podrían añadirse otros elementos a los ya mencionados. Por ejemplo, el relativo auge de la historia de las disciplinas con las aportaciones del grupo Nebraska, las exposiciones y publicaciones conmemorativas de la creación de tal o cual instituto de segunda enseñanza, los trabajos — sobre todo para la segunda mitad del siglo XX — de José Ignacio Cruz o Antonio Francisco Canales, entre otros, o algunas jornadas concretas de índole regional como las celebradas en Zaragoza en 2009 y 2011. ${ }^{3}$ Todos estos elementos, como los mismos editores confiesan, han hecho posible la elaboración del libro que comentamos. Sus editores y autores se reconocen como enanos a hombros de gigantes; es decir, como continuadores, adicionadores y perfeccionadores de una tradición investigadora que ofrece

\footnotetext{
2 Leoncio López-Ocón, Victor Guijarro y Mario Pedrazuela (eds.), Aulas abiertas. Profesores viajeros y renovación de la enseñanza secundaria en los países ibéricos (Madrid: Dykinson, 2018), 11.

3 Guillermo Vicente Gerrero (coord. y ed. lit.), Historia de la Enseñanza Media en Aragón (Zaragoza: Institutición «Fernando el Católico», 2011) y, Guillermo Vicente Gerrero, Estudios sobre la enseñanza secundaria en Aragón (Zaragoza: Institución «Fernando el Católico», 2012).
} 
diversas líneas y variantes. Eso les honra, pero al comentarista de la obra le corresponde destacar que no estamos ante una acción aislada, sino ante un producto más de lo que sin duda es hoy una de las líneas de trabajo más prometedoras en relación con la historia de la segunda enseñanza desde su configuración como nivel educativo a mediados del siglo XIX hasta la guerra civil. Nos referimos a la línea de investigación iniciada con el programa I+D CEIMES «Ciencia y educación en los institutos de enseñanza secundaria a través de su patrimonio cultural (1837-1936)» financiado por la Comunidad de Madrid entre 2008 y 2011.

En efecto, si el resultado más visible de dicho programa fue la publicación del libro colectivo Aulas con memoria. Ciencia, educación y patrimonio de los institutos históricos de Madrid (1837-1936), ${ }^{4}$ el hecho de que su contenido fuera más allá del límite institucional y espacial indicado en el título, así como los retos y la dinámica propia de la investigación realizada, llevaron al grupo CEIMES a centrar su atención en los cambios e innovaciones que tuvieron lugar en la enseñanza secundaria en el período 1900-1939, en especial a consecuencia de la creación en 1907 de la Junta para Ampliación de Estudios e Investigaciones Científicas (JAE). Y, con ello, a emprender un nuevo proyecto de investigación titulado «Educación "integral" para los jóvenes bachilleres: cambios producidos por la JAE en la enseñanza secundaria (1907-1936)», producto del cual fueron el libro colectivo Aulas modernas. Nuevas perspectivas sobre la reforma de la enseñanza secundaria en la época de la JAE (1907-1939), ${ }^{5}$ y la creación del sitio web https://ceies.cchs.csic.es/?q=inicio ( $D$ Diccionario de profesores de instituto vinculados a la JAE»). A dicho proyecto siguió, continuando la línea de trabajo iniciada en 2008, el titulado «Dinámicas de renovación educativa y científica en las aulas de bachillerato (1900-1936): una perspectiva ibérica», en el que se abría la puerta a investigadores portugueses. Sus resultados se ofrecen en el libro que comentamos, el tercero de una serie que nos lleva desde las «aulas con memoria» a las «aulas abiertas» con el paso intermedio por las «aulas modernas». Un libro centrado, por parte española, en «las prácticas educativas» del «largo centenar de

\footnotetext{
${ }^{4}$ Leoncio López-Ocón, Santiago Aragón y Mario Pedrazuela (eds.), Aulas con memoria. Ciencia, educación y patrimonio en los institutos históricos de Madrid (1837-1936) (Madrid: CEIMES / CSIC / Comunidad de Madrid, 2012).

${ }^{5}$ Leoncio López-Ocón (ed.), Aulas modernas. Nuevas perspectivas sobre la reforma de la enseñanza secundaria en la época de la JAE (1907-1939) (Madrid: Universidad Carlos III /Dykinson, 2014).
} 
profesores y profesoras» que «disfrutaron de una pensión de la JAE para viajar al extranjero para formarse como investigadores y aprender nuevos métodos de enseñanza» $\mathrm{y}$ "fueron la punta de lanza de ensayos de renovación educativa en las aulas de bachillerato» (pp. 15 y 17) y, por parte portuguesa, en los becados por la Junta de Educação Nacional.

La obra consta de cuatro partes. La primera incluye dos textos sobre «los viajes con retorno» del profesorado de enseñanza secundaria becado por la JAE, con especial atención a las materias de Ciencias Naturales, Agricultura, Física y Química, Matemáticas, Filosofía, Lengua y Literatura española, Latín y Lenguas modernas, del que son autores Leoncio López-Ocón, Víctor Guijarro y Mario Pedrazuela, y la renovación pedagógica y científica en los liceos portugueses gracias a las becas de la Junta de Educação Nacional (1929-1936), a cargo de Quintino M. Junqueira Lopes. La segunda («La adopción de nuevas prácticas y materiales de enseñanza»), consta de seis aportaciones de Víctor Guijarro ( La interacción personal con el objeto científico y la acción educativa: notas, máquinas dóciles y manuales, 1885-1910»), Isabel Malaquías ( $P$ Percursos de modernização no ensino das ciências físicas nos liceus, 1900-1930»), Inês Gomes ("A sala de aula e as ciencias naturais. $\mathrm{O}$ ensino experimental nos liceus portugueses: realidade ou utopia?»). José Pedro Marín («Efectos de renovación educativa en la enseñanza de la Historia Natural del Instituto de Murcia a través del relato de su material científico»), Francisco J. Frutos, Carmen López, Beatriz González y Manuela Carmona («La linterna de proyección y la renovación científica de los bachilleres españoles en el primer tercio del siglo XX») y Juana $\mathrm{M}^{\mathrm{a}}$ González («Literatura y cine en las aulas de secundaria. La colaboración de Guillermo Díaz Plaja en la Revista Internacional de Cinema Educativo, 1929-1934»). La tercera parte consta de un solo artículo de Francisco Villacorta sobre «Profesorado, título y carrera: avances y fracturas de la segunda enseñanza pública en España en los siglos XIX y XX». Por último, en la cuarta parte se ofrecen las biografías académicas (con expresión de sus obras y bibliografía) de 55 docentes de Institutos españoles becados por la JAE de diez o materias o campos disciplinares, que pueden consultarse, junto con otras biografías y documentación complementaria, en el mencionado sitio «JAEeduca. Diccionario de profesores de instituto vinculados a la JAE (1907-1936»). 
En los tres libros mencionados, con su origen en el programa CEIMES, el Instituto-Escuela ha ido siendo objeto de una atención progresiva. No podía ser de otro modo. Tomar por objeto de estudio los cambios e innovaciones acaecidos en la segunda enseñanza durante el primer tercio del siglo XX, y el papel desempeñado en los mismos por la JAE, tenía que conducir necesariamente a la institución educativa, dependiente de la Junta, creada en 1918 con el doble fin de servir de centro de ensayo, experimentación y reforma, uniendo en un solo establecimiento educativo, las enseñanzas primaria — «sección preparatoria»— y media, y de formación del profesorado de segunda enseñanza mediante la fórmula del «aspirantado»: el Instituto-Escuela. Por si ello no fuera suficiente, el centenario de su creación tendría lugar en 2018. Una ocasión propicia para rememorar lo que fue y lo que pudo ser la institución docente de segunda enseñanza que, junto con la Escuela Normal de Filosofía (1846-1852), sigue siendo uno de los referentes modélicos, desde un punto de vista histórico, de la formación del profesorado de educación secundaria, una cuestión todavía sin resolver ni hallar un modelo medianamente satisfactorio.

Con tal motivo, tuvo lugar en 2018 una exposición conmemorativa en el Museo Nacional de Ciencias Naturales, a la que corresponde el libro-catálogo que comentamos en segundo lugar. ${ }^{6}$ En esta obra colectiva colaboran docentes e investigadores de diversos centros educativos, en especial del Instituto de Educación Secundaria «Isabel la Católica», heredero de las instalaciones e infraestructuras del Instituto-Escuela, Sección Retiro, ${ }^{7}$ historiadores de la educación e historiadores de la ciencia.

Los temas abordados no solo cubren todos los aspectos relevantes de esta institución educativa a lo largo de sus veintiún años de existencia, sino otros hasta ahora poco o menos conocidos. Así, tras un primer capítulo de índole general sobre «La escuela y la renovación pedagógica en España en el primer tercio del siglo XX», a cargo de Alejandro Tiana y Gabriela Ossenbach, se disponen otros sobre «Los orígenes del Instituto-Escuela: los grupos de niños de la Residencia de Estudiantes» (Álvaro

\footnotetext{
6 Encarnación Martínez Alfaro, Leoncio López-Cabrera y Gabriela Ossenbach Sauter (eds.), Ciencia e innovación en las aulas. Centenario del Instituto-Escuela (1918-1939) (Madrid: CSIC/UNED, 2018).

7 Encarnación Martínez Alfaro, Un laboratorio pedagógico de la Junta para Ampliación de Estudios. El Instituto-Escuela. Sección Retiro de Madrid (Madrid: Biblioteca Nueva, 2009).
} 
Ribagorda), «Los inicios de una acción educadora de la JAE en 1918» (Leoncio López-Ocón), «Educar y experimentar» (Santos Casado y Carmen Massip), «La enseñanza a través de las imágenes en el Instituto-Escuela» (Javier Frutos), «La Biblioteca del Instituto-Escuela. Sección Retiro» (Encarnación Martínez), «De la Institución Libre de Enseñanza al Instituto-Escuela. La lengua y la literatura en el Instituto-Escuela de Madrid» (Mario Pedrazuela), «El Instituto-Escuela y el ideal de la arquitectura escolar» (Francisco J. Rodríguez), «Un colectivo de prestigio: el profesorado del Instituto-Escuela de Madrid» (José Damián López y María Ángeles Delgado), «Las alumnas del Instituto-Escuela» (María Poveda), «Los cuatro Institut-Escola de Cataluña» (Salvador Domènech), «Modelo pedagógico y prácticas didácticas en el Instituto-Escuela de Valencia» (Alejandro Mayordomo), «El Instituto-Escuela de Sevilla» (Carlos Algora), «El uso didáctico del Instituto-Escuela. Sección Retiro» (Alonso Marín, Lucía López y Enrique Arjona), y «Trayectorias vitales y profesionales de alumnos del Instituto-Escuela de Madrid» (Leticia Cabañas). Al final, tras los quince trabajos mencionados se incluye un anexo con la relación de objetos expuestos. ${ }^{8}$

El tercero de los libros reseñados nace y se elabora en el seno del programa CEIMES sobre el patrimonio y la cultura material de los institutos de segunda enseñanza en la España del siglo XIX y el primer tercio del siglo XX. Ofrece sin embargo, en relación con los anteriores, algunas peculiaridades. ${ }^{9}$ En primer lugar, es de autoría individual y cubre desde 1845 —es decir, desde el Plan Pidal y la acción de Antonio Gil de Zárate al frente de la Dirección General de Instrucción Pública- hasta 1930. En segundo lugar, se centra y profundiza en un tema, el del objeto científico, inserto en el más amplio de la cultura material de las instituciones docentes. Una cuestión en la que, aun existiendo trabajos más restringidos temporal e institucionalmente, creemos que el libro

\footnotetext{
${ }^{8}$ La conmemoración del centenario de la creación del Instituto-Escuela ha sido, asimismo, el origen de otra exposición, a cargo de la Fundación Francisco Giner de los Ríos / Institución Libre de Enseñanza, que todavía no ha abierto sus puertas en el momento de redactar estas líneas, y cuyo libro catálogo, ya publicado (Laboratorios de la nueva educación. En el centenario del Instituto-Escuela. Madrid, 2019), no se incluye en esta reseña por haber participado como autor en uno de sus capítulos, así como de un libro de Ángel S. Porto Ucha y Raquel Vázquez Ramil, En el centenario del Instituto-Escuela. Obra educativa de los institucionistas (Soria: CEASGA, 2019).
}

9 Víctor Guijarro Mora, Artefactos y acción educativa. La cultura del objeto científico en la enseñanza secundaria en España (1845-1930) (Madrid: Dykinson, 2018). 
marca un antes y un después en las investigaciones que se lleven a cabo en este ámbito. La razón es bien simple: cubre, como seguidamente se detalla, no solo los procesos de adquisición y uso de dicho material, sino también su significado y valoración.

En los recién creados Institutos de segunda enseñanza y, tras el plan de estudios de 1845, el gobierno acometió en 1847 un plan-modelo de adquisición de material científico - recogido en un apéndice final del libro- para los gabinetes y laboratorios de estas nuevas instituciones educativas, al que posteriormente seguirían otros planes. Como indica Víctor Guijarro en la «Introducción», la posesión de estos aparatos y material «se asoció inmediatamente con el cumplimiento» del «ideario» o «valores defendidos por las políticas educativas liberales», entre los que destacaba «la oposición al intelectualismo y la promoción de la experiencia y la práctica». Por supuesto, «la acción docente reveló algunos desajustes en la maquinaria político-industrial. En los procesos de aprendizaje y familiarización con los aparatos, los educadores reinterpretaban y extendían los propósitos originales revelados en las instrucciones de los manuales y catálogos de los fabricantes». Un desajuste agudizado cuando hacia 1880 en Europa y América se produce «una crisis en el sostenimiento estatal del material de los gabinetes» y emerge «un interés creciente por los recursos visuales» (pp. 13-14).

Es en este contexto, el del juego de relaciones entre las políticas ministeriales, las empresas productoras y comercializadoras del material científico, los procesos de apropiación, reinterpretación y usos de dicho material, el profesorado y la acción docente en el que se desenvuelve una obra que por su enfoque, como quedó dicho, estimamos que servirá de modelo metodológico y de análisis para futuras y similares investigaciones. Todo ello en ocho capítulos cuyos títulos definen su contenido: «La formación del objeto científico educativo» (la prueba demostrativa, pensamiento y acción y el debate en España), «La mediación política» (recursos, objetos, procedimientos), «El fabricante mediador y la industria de la enseñanza científica» (reproducción de estándares, catálogos, proveedores, intermediarios, representantes y agentes), «Dinámicas de los gabinetes: la apropiación material» (primera etapa del gabinete, 18451885; coleccionismo y segunda etapa, 1886-1906; reactivación y control estatal, 1907-1930), «Profesores, instrumentos y formas de vida académica» (del almacén al museo, viajes y exposiciones, un sistema universal 
de pesas y medidas, artefactos frente a manuales), «Los objetos en el aula» (experiencias, aulas activas), "Artefactos y formación del imaginario científico: mediación y autoridad» (asociaciones de disciplinas, autoridad, representación, tecnología y pensamiento visual), y «Artefactos y formación del imaginario científico: la difusión de valores» (cuerpos y vigor físico, mentes y la medida de las capacidades, los artefactos de la psicología experimental).

En el año 2010, en un trabajo escrito unos tres años antes, llevaba a cabo una revisión historiográfica del papel desempeñado por la JAE en el ámbito de la pedagogía y las experiencias o renovación educativa en la España del primer tercio del siglo XX. ${ }^{10}$ En sus páginas finales ofrecía una síntesis de los «nuevos enfoques» surgidos en torno al tema, así como, en un intento de orientar las futuras investigaciones, de algunos de los campos y cuestiones que restaban por tratar. La realidad, gracias sobre todo al programa CEIMES, liderado por Leoncio López-Ocón, ha superado lo que allí señalaba. Quedaba mucho por decir sobre la pedagogía y la educación en la JAE y sigue quedando. Como sigue quedando en relación también con la segunda enseñanza y otros niveles educativos. Los tres libros que comentamos así lo muestran. Y así lo indica el nuevo proyecto de investigación del grupo CEIMES para los años 20192022, financiado por el Ministerio de Ciencia, Innovación y Universidades y codirigido por Leoncio López-Ocón y Álvaro Ribagorda, sobre «Desafíos educativos y científicos de la Segunda República española: internacionalización, popularización e innovación en universidades e institutos». No solo continua en el tiempo otros proyectos anteriores, sino que los amplía en una dirección, la de la docencia e investigación científica universitaria, plena de sentido y coherente con lo hasta ahora realizado.

Antonio Viñao

Universidad de Murcia avinao@um.es

\footnotetext{
10 Antonio Viñao, «Pedagogía y experiencias educativas en la JAE: revisión historiográfica y nuevos enfoques», en 100 JAE. La Junta para Ampliación de Estudios e Investigaciones Científicas en su centenario, eds. Juan Manuel Sánchez Ron y José García Velasco (Madrid: Fundación Francisco Giner de los Ríos / Residencia de Estudiantes), t. II, 597-635.
} 